\title{
Qualities of Effective Leadership in Higher Education
}

\author{
Simon A. Black \\ Department of Human Resources, University of Kent, Canterbury, UK \\ Email: s.black@kent.ac.uk
}

Received 17 April 2015; accepted 13 June 2015; published 16 June 2015

Copyright (C) 2015 by author and Scientific Research Publishing Inc.

This work is licensed under the Creative Commons Attribution International License (CC BY).

http://creativecommons.org/licenses/by/4.0/

(c) (i) Open Access

\begin{abstract}
The leadership of Higher Education institutions has been placed under increasing scrutiny since the 1980s with the expansion of student numbers, changes in funding for student places, increased marketization and student choice, and continuing globalisation of the sector. In this climate of change Higher Education institutions have been required to consider how to develop their leaders and what might be appropriate leadership behaviour to enable adaptation to these new circumstances. When the various paradigms of leadership encountered in the Higher Education sector are compared with established leadership theory and practice it is possible to identify further intricacies in the development of Higher Education leaders. Further consideration of practicalities within Higher Education identifies whether competence frameworks might assist in leadership development. An examination of a recently-developed comprehensive framework of leadership capabilities applied in an alternative sector leads to an evaluation as to whether the same constructs apply to the demands placed upon leaders in Higher Education. Analysis demonstrates that, with minor changes in terminology, the constructs remain appropriate and valid. The definitions of activities and behaviours offer insight into how Higher Education leaders could be developed and therefore form a potential framework of leadership capabilities for Higher Education.
\end{abstract}

\section{Keywords}

Higher Education, Systems Thinking, Competencies, Transformation, Competence Framework

\section{Introduction}

There has been a growing interest in the role of leaders within Higher Education (HE) institutions in recent years, driven both by the influence of HE institutions in developing learners who later develop as leaders in wider society, and by the changing shape of HE leadership itself in the face of global challenges in the sector. Several contextual shifts have occurred within the Higher Education sector in recent decades, particularly globalisation 
of the market and internationalisation of institutions, development of for-profit private institutions, cutbacks in public funding and increased cross-border academic mobility (Gibbons, 1998; Middlehurst, 1999; Schofer \& Meyer, 2005; Altbach, 2011). Since the 1990s the leadership approach encountered in UK Higher Education institutions has been placed under increasing scrutiny with the need to adapt to a huge expansion in student numbers and the development of a fee-paying culture (Deem, 1998) which has changed expectations to a more outward-facing student focused approach, largely at odds with the traditional inward-looking collegial approach (Davies, Hides, \& Casey, 2001). This change has driven a move in UK institutions from "administration” (keeping things ticking over) to a pervading "management culture” ever since (Clegg \& McAuley, 2005), with comparable change in management functions of North American colleges observed since the 1980s (Amey, 2006).

Leaders in HE institutions have to examine how to better lead their organisations, and must also find approaches which fit best in the HE context; i.e. the most effective leadership approach. However, this is not straightforward since there is no clear consensus on the definition of leadership (Kennedy, 1994) and the parallel and sometimes interweaving evolution of leadership ideologies complicate the picture. Over the past 100 years several broad philosophies have emerged and can be seen to persist in various guises in modern organisations:

1) "Command-and-control" leadership has proliferated since the $19^{\text {th }}$ Century industrial era, drawing on rules, incentives, threats, contracts, and standards (Macdonald, 1998), evolving into quasi-military concepts through the 1940s (Kennedy, 1994). This "scientific management" approach focuses on efficiency of the organizational "machine"; managers make decisions, specialists work in separate functions, and work is continually simplified.

2) "Behavioural" theories emerged in the 1950s, based upon more complete considerations of human nature and motivation (McGregor, 1957; Herzberg, 1976). Situational leadership (Hersey \& Blanchard 1969) called for adaptation of style relative to staff competence and the task, whilst Adair (1979) added considerations of team dynamics into this context.

3) "Transactional-transformational" models in the 1970s (Burns, 1978; Bass, 1997) involve reinforcement of performance ("transactional” behaviour), alongside understanding followers, and building their self-worth and focus ("transformational” behaviors). Credibility, vision, values, competence, judgment, experimentation, and engagement of staff are emphasised (Peters \& Waterman, 1982; Kouzes \& Posner, 2007; Bennis 1999, 2009).

4) "Transformational leadership" and the emphasis of transformational behavior has become the sole dominant paradigm over the past 20 years (Kennedy, 1994; Tourish, 2008). Leaders are portrayed as heroes (Slater, 1999; Kanter, 2003) and are encouraged to transform the loyalties and behaviors of their staff through a shared organizational culture. Negative effects may arise however; dialogue may become stifled, problem-solving may diminish (Seddon, 2003; Tourish, 2008) and people can be perceived as the source of problems (Heifetz \& Laurie, 1997). The coercion of people is reminiscent of command-and-control's structures and rules (Black, Groombridge, \& Jones, 2011).

5) "Systems Thinking" was applied to management in the 1920s (Shewhart, 1931) and further developed in the 1940s by Deming (1982). A Systems Thinking leader aims to optimize links between manager behavior, rules, structure, decision-making, skills, methods, and results (Senge, 1990; Womack \& Jones, 1996; Oakland, 2001). Leaders aim to "work on the system" which is a fundamental change from the mantra of command-and-control and transformational leaders which emphasises "working on people" (Seddon, 2003).

In order to examine the relevance of leadership constructs within the HE environment it is necessary to compare the existing understanding of leadership within HE alongside contemporary leadership theory and practice. Thereafter, where comprehensive leadership competence frameworks already exist (i.e. descriptions of leadership activities and capabilities) these could be tested in relation to the demands of the HE sector. A recently developed sector-specific model in biodiversity conservation (Black, Groombridge, \& Jones, 2011) provides just such a potential comparator. This discussion examines whether, after suitable translation of terminology, the subsequently developed HE leadership framework remains valid, robust and relevant when tested in the context of leadership challenges encountered in Higher Education.

\section{The Leadership Context in Higher Education}

Leadership roles in academic institutions have a number of anomalies; whilst traditional senior executive roles (e.g. Vice-Chancellor, Chief Executive, President, Vice-President, pro-Vice Chancellor) resonate with executive 
roles encountered in other sectors, academic leadership roles (such as Deans or Heads of School) are unusual and commonly have complications such as transitory nature of role-holders (for example on a 3-year rotating basis, much like a secondment). Also, traditionally in some situations, academic roles can be given on an almost honorary basis as "first among equals" to a senior or established professor (Davies, Hides, \& Casey, 2001). Faculty positions usually combine the role of teacher, scholar, researcher and institutional citizen (Astin \& Astin, 2000) all of which have leadership responsibility in some form or other, either explicitly or implicitly specified within the role. Academics may also develop additional external leadership roles within subject discipline peer-groups, research collaboration project teams and external professional bodies.

Aside from the nuanced challenge of the traditional structural legacy, the demands of a globalised, market-driven HE sector have put pressure on a need for effective and efficient use of resources throughout the institution, in academic areas as well as in service areas (Davies, Hides, \& Casey, 2001). The "student experience”, namely the integrated learning, lifestyle, social and developmental provision to students demands a much more integrated arrangement of work between academic and service departments (Astin \& Astin 2000; Tam, 2001). In parallel with the core teaching and research activity of the institution, professional service departments have become increasingly important in the provision of student services, accommodation, sports facilities, administration and management of student finance as well as university functions such as human resources, finance, marketing, estates management, coordination of research funding and engagement with business. Leaders in these areas are generally more focused on delivering operational efficiencies.

The changing context has further highlighted the inadequacy of traditional leadership approaches in HE. The “first among equals" roles (Davies, Hides, \& Casey, 2001) taken by senior academics is largely based around principles of collegiality, yet this does not fit well with the demand for efficient and effective use of resources. Indeed the rise of "managerialism" in Higher Education, with its culture of metrics, policy, audit and an emphasis on flexibility, transparency and marketization has caused consternation, or at least discomfort, within the sector due to this clash of cultures and working practices (Deem, 1998; Garforth \& Kerr, 2009). This should not be unexpected, since middle manager communities (whether academic or professional services) usually have an intense sense of ownership and identity with the long term interests of the organisation and the welfare of subordinates (Huy, 2001; Mintzberg, 2009b).

The conceptual split between leadership ("good”) and managerialsim ("bad”) might be a consequence of defensiveness on the part of those who are managed (i.e. academics) and on the other hand, the tendency of the techniques of management to be seen to become an end in itself (Krantz \& Gilmore 1990; Deem, 1998). However in contemporary management and leadership literature it is increasingly recognised that separating leadership from management is unhelpful; both should complement each other (Bennis, 2009; Mintzberg 2009a, 2009b), linking strategic vision and organizational machinery (Krantz \& Gilmore 1990), and this means that having suitably complementary constructs of leadership and management becomes important.

At the same time institutions’ most senior leaders have a key emerging challenge. As much as representing and symbolising the university externally (i.e. the traditional role of Vice Chancellors and their immediate peers), senior leaders also need to model the principles of the institution (Kouzes \& Posner, 2007; Astin \& Astin, 2000; Altbach, 2011). As institutions evolve to the needs of a globalised and user-led market, the identity and principles of the institution may in many instances need to be redefined. However, in order to achieve this, leaders in senior executive and professional service roles are required to navigate the priorities of academic colleagues. Ideally this will be attained through the development shared beliefs and values so that the institution can operate smoothly without being encumbered by bureaucratic structures (Astin \& Astin, 2000), yet the reality is often somewhat different.

\section{Typical Leadership Paradigms in Higher Education}

The challenges experienced in HE over recent decades have led to the emergence of various leadership approaches within the sector and can be observed in many HE institutions across all regions, whether research-led, teaching-led, large or small, specialised or multi-faculty.

\subsection{Hierarchical Models}

One of the most typical approaches encountered in HE institutions is the authority and power model associated with hierarchy (Astin \& Astin, 2000). Teacher-centred approaches tend to equate to this top-down, autocratic 
view of leadership (Amey, 2006). The negative aspects arising from this type of command-and-control approach have been previously highlighted. Furthermore, in higher education, the development of learning communities, encouraging social change or inspiring in students a sense of being part of a global society, demands a much more adaptive and open sense of leadership which is contrary to the hierarchical command-and-control mind-set. Academic leaders need to dispense with "positional" authority, normally associated with command-and-control leadership, in order to enable more transformational learning approaches to be undertaken by students (Amey, 2006). It has also been suggested that a command-and-control approach is particularly unsuitable and counterproductive when managing academic colleagues (Goffee \& Jones, 2009).

\subsection{Individualistic Models}

Individualistic leadership is based on personal status and professional recognition, is usually encountered within academic faculty positions, and has been identified in American colleges as a key reason for driving the higher value of research versus teaching (Astin \& Astin, 2000). The balancing of teaching and research commitments is a contentious theme in many HE institutions. The negative effect of individualistic leadership is that it makes collaboration more difficult, since competition is seen as more rewarding. Additionally the individualistic paradigm is biased against some minorities, particularly women, who may take career breaks which affect their accumulation of research achievements. This is a particular issue in science and technology where the progression of women is notably negatively affected, such that in the UK specific national initiatives aim to develop women in science, technology, engineering, maths and medicine (Garforth \& Kerr, 2009; ECU, 2015). Similar debates around gender and ethnicity continue in institutions in the USA and Europe (Etzkowitz et al., 1994; Amey, 2006; D’Amico, Vermigli, \& Canetto, 2011).

\subsection{Collegial Models}

Collegiality is a term used in two distinct ways: sometimes it refers to a system of governance driven by consensual decision making and on other occasions it refers to mutual supportiveness among staff (Bryman, 2007). Whilst the latter peer-support is valued in academic communities (Bryman, 2007), the former is the usual structural outcome (i.e. a committee or bureaucratic-based approach) which paradoxically drives the general dislike in academic circles of "administrative” work (Astin \& Astin, 2000). Clegg and McAuley (2005) assimilate these by defining the Collegial concept as one where academics work together whilst retaining their individual interests, eschewing any attempt to be actively managed, so that individuals are left to do their own thing as long as traditional rituals and duties are observed. Essentially the collegial approach is pursued for the benefit of the community itself, not users or external demands placed upon that community (such as expectations of the government, students, industry, or funding bodies) and this raises difficulties for the institution itself.

\subsection{Collaborative Models}

Developments in leadership thinking over the past 30 years have emphasised collaborative approaches (Heifetz \& Laurie, 1997; Bennis, 1999, 2009; Kouzes \& Posner 2007) yet Higher Education has been relatively slow to pick up the importance of this principle, largely due to the traditional functional specialism engendered in faculty structures. Over the last 20 years collaboration appeared to be initiated, expected and driven by research funders, rather than institutions themselves (Defazio, Lockett, \& Wright, 2009). Within academic roles successful leaders are increasingly seen to be those more able to develop collaborative partnerships and to establish networks in a non-hierarchical manner (Amey, 2006), whilst retaining accountability and evidence-based approaches which demonstrate what does, and does not work. The traditional model where senior professors elected from their own ranks for short terms of office is perhaps no longer practical in the light of the now myriad skills demanded in an effective university leader (Altbach, 2011).

\subsection{Transformative Models}

Transformational leadership models have tended to dominate the understanding of leadership within the HE sector (Astin \& Astin, 2000) and tend to resonate positively with their apparent foundation upon human interactions, which matches the demands of faculty and campus-based leadership roles. The expectation of "emotional intelligence” in leadership (Goleman, 1997) is attractive; HE institutions are essentially in the business of human 
interaction. At an academic level, the "learner-centred" approach to education matches the adaptive concepts of transformational leadership (Amey, 2006). Additionally, the transformational approach is also perceived to match with the challenges of a changing sector (globalisation and user-driven demands) and is a leadership approach which will better enable the creative solutions which are needed to meet those challenges. Certainly the role of HE institution leaders as change agents has become increasingly important (Amey, 2006).

\section{Assimilating Models of Leadership for Higher Education}

Fortunately our understanding of leadership in other sectors can offer assistance in assimilating which principles of leadership can be applied in the HE context, and how. An effective leader needs to apply both transformational and transactional leadership approaches (Bass \& Avolio, 1993) depending on the different individuals and tasks being undertaken at various points in time. The practical challenge for the leader is to be able to perceive which elements to manage within the context of each particular situation (e.g. people, task, team, and other contextual information).

One of the more heavily scrutinized frameworks of leadership is offered by Kouzes and Posner (2007). Their five practices of Exemplary Leadership can be compared to existing models devised within the HE sector (Table 1). The comparison illustrates that the breadth of leadership challenge in HE is congruent with Kouzes and Posner's (2007) model, but the detail within each element of the HE models is less clearly defined. For example, how a shared vision is developed and implemented in $\mathrm{HE}$ is less well defined even within the well-bounded confines of an academic department (Bryman, 2007) than is understood in general leadership theory and practice. Perhaps more starkly, the ways in which HE leaders can influence and seek improvements and innovation is much less well defined in current HE frameworks (Table 1). Similarly how HE institutions encourage and recognise efforts is poorly understood aside from traditional academic promotion pathways.

Leadership competency frameworks, where available, can be helpful guides, but if used require caution (Bryman, 2007). For example, knowing that a leader has to cultivate personal integrity may be useful, but how one goes about establishing and maintaining personal integrity is a different matter. Also in some models the aspects of leadership appear to clash, such as the balance between developing one's own research credibility and the ability to also manage a department (Bryman, 2007); aside from potential goal displacement, time constraints alone may work one priority against the other.

In addition, a competence framework needs to appreciate the contextual notion of leadership (Tannenbaum \& Schmidt, 1973). For example, would a list of effective leadership behaviours remain valid across the diverse contexts within which university leaders are likely to find themselves (Bryman, 2007) such as in diverse professional service, student-support, academic or senior executive roles? Does leadership behaviour transcend the roles of senior executives and vice-chancellors, departmental or school leaders and other professional positions? How would a leadership framework accommodate sector-typical anomalies such as rotating roles (e.g. 3 year posts) for people in academic leadership positions (Bryman, 2007)?

A further risk is that in following a set of competencies a leader will focus on "doing leadership" rather than ensuring that effective work get done (Seddon, 2003). This means that a list of effective leadership practices must itself focus the leader on the appropriate purpose of their role. Kouzes and Posner's (2007) framework attempts this by bringing the importance of shared vision, principles and clear goals to the forefront. However it is strongly argued by many leadership commentators that a focus on organisational purpose is the primary test of good leadership (Peters \& Waterman, 1982; Bennis, 1999; Scholtes, 1998; Hamel, 2009).

A focus on purpose is the foundation of Systems Thinking which is rarely encountered in HE leadership yet which is extensively discussed in management literature (Deming 1982; Senge, 1990; Womack \& Jones, 1996 ; Seddon, 2003). Understanding the organisation as a system is important since a suitable leadership approach is unlikely to emerge in the natural order of things. For example, if collaboration is required, then the institution must be seen to value that activity (Astin \& Astin, 2000); only then will leaders be inclined to pursue collaborative work. If the general system (rules, measures of performance, promotion criteria, goals, procedures) suggests a different set of priorities, then a different outcome will emerge (Seddon, 2003). Put a good performer in a bad system and the system wins every time (Rummler \& Bache, 1995).

\section{Developing a Framework of Relevant Leadership Capabilities}

Most HE institutions, to a greater or lesser extent, are considering which leadership approaches are most appro- 
Table 1. Comparison of typical HE leadership frameworks with a general model of leadership.

\begin{tabular}{|c|c|c|}
\hline $\begin{array}{l}\text { Five Practices of Exemplary Leadership } \\
\text { (Kouzes \& Posner, 2007) }\end{array}$ & $\begin{array}{c}\text { Transformative } \\
\text { Leadership in HE } \\
\text { (Astin \& Astin, 2000) }\end{array}$ & $\begin{array}{l}\text { Effective University Department Leadership } \\
\text { (Bryman, 2007) }\end{array}$ \\
\hline $\begin{array}{l}\text { Model the Way } \\
\text { - } \quad \text { Establish principles on treating people } \\
\text { - } \quad \text { Establish principles for pursuing goals } \\
\text { - } \quad \text { Set standards of excellence } \\
\text { - } \quad \text { Set interim goals and quick wins } \\
\text { - } \quad \text { Unravel bureaucracy } \\
\text { - } \quad \text { Signpost the way to go } \\
\text { - } \quad \text { Create opportunities for success }\end{array}$ & $\begin{array}{l}\text { - Self-knowledge } \\
\text { - Authenticity/integrity }\end{array}$ & $\begin{array}{l}\text { - Acting as a role model and having credibility } \\
\text { - Being considerate } \\
\text { - Treating academic staff fairly and with } \\
\text { integrity } \\
\text { - Being trustworthy and having personal } \\
\text { integrity }\end{array}$ \\
\hline $\begin{array}{l}\text { Inspire a Shared Vision } \\
\text { - } \quad \text { Belief that one can make a difference } \\
\text { - } \quad \text { Envision the future with a unique image } \\
\text { - } \quad \text { Enlist others in these dreams } \\
\text { - } \quad \text { Get people life into the vision } \\
\end{array}$ & $\begin{array}{l}\text { - Shared Purpose } \\
\text { - Competence }\end{array}$ & $\begin{array}{l}\text { - Clear sense of direction/strategic vision } \\
\text { - Preparing department arrangements to } \\
\text { facilitate the direction set } \\
\text { - Communicating well about the direction the } \\
\text { department is going }\end{array}$ \\
\hline $\begin{array}{l}\text { Challenge the Process } \\
\text { - } \quad \text { Seek opportunities to make changes } \\
\text { - } \quad \text { Innovate to improve the organisation } \\
\text { - } \quad \text { Experiment and take risks } \\
\text { Accept mistakes, disappointments and failures } \\
\text { as opportunities to learn. }\end{array}$ & $\begin{array}{l}\text { - A learning environment } \\
\text { - Disagreement with } \\
\text { respect }\end{array}$ & $\begin{array}{l}\text { - Advancing the department's cause with } \\
\text { respect to constituencies internal and } \\
\text { external to the university and being proactive } \\
\text { in doing so }\end{array}$ \\
\hline $\begin{array}{ll}\text { Enable others to Act } \\
\text { - } & \text { Foster collaboration } \\
\text { - } & \text { Build team spirit } \\
\text { - } & \text { Actively involve others }\end{array}$ & $\begin{array}{l}\text { - Collaboration } \\
\text { - Division of labour }\end{array}$ & $\begin{array}{l}\text { - Creating a positive and collegial work } \\
\text { atmosphere in the department } \\
\text { - Allowing the opportunity to participate in } \\
\text { key decisions/encouraging open } \\
\text { communication }\end{array}$ \\
\hline $\begin{array}{l}\text { Encourage the Heart } \\
\text { - Keep hope and determination alive } \\
\text { - } \quad \text { Recognise individuals' contributions } \\
\text { - } \quad \text { Share rewards within the team } \\
\text { - } \quad \text { Celebrate accomplishments } \\
\text { - } \quad \text { Make people feel like heroes }\end{array}$ & $\begin{array}{l}\text { - Commitment } \\
\text { - Empathy/understanding } \\
\text { of others }\end{array}$ & $\begin{array}{l}\text { - Providing feedback on performance } \\
\text { - Making academic appointments that enhance } \\
\text { department's reputation } \\
\text { - Providing resources for adjusting workloads } \\
\text { to stimulate scholarship and research }\end{array}$ \\
\hline
\end{tabular}

priate in enabling their organisation to adapt to a new climate of globalisation and a market driven by student choice. When considering models proposed in other sectors, one of the more pragmatic and detailed recent leadership frameworks is offered by Black, Groombridge and Jones (2011) who sought to explain the leadership capabilities needed in managing wildlife conservation. The potential relevance of their framework warrants further exploration, since wildlife conservation work is characterized by expert personnel, long-term aims, short-term priorities, external funding, and a multi-stakeholder environment exposed to national, social, political and economic externalities (Black, Groombridge, \& Jones, 2013; Black \& Copsey, 2014a; 2014b), all of which resonate with the demands placed on HE institutions.

\subsection{Basis of Comparison-Construct Validity}

Although clearly a different sector in many respects to HE, managers and executives in the wildlife sector have a similarly underdeveloped understanding of leadership and across the sector there is a relatively low level of capacity in terms of leadership and management capability (Black, Meredith, \& Groombridge, 2011), mirroring the HE sector. Furthermore, the framework developed by Black, Groombridge and Jones (2011) draws on a broad range of leadership theory including Systems Thinking which is largely absent in current HE leadership and management models.

The Black, Groombridge and Jones (2011) framework also offers a broader scope than Kouzes and Posner (2007) for addressing operational, cultural, organisational and resourcing challenges faced in HE. Indeed 14 ca- 
pability items in the framework (items 2, 6, 8, 10, 17, 27, 28, 29, 30, 33, 34, 35, 36, 41) are outside the scope of Kouzes and Posner's (2007) model. This suggests that the Black, Groombridge and Jones (2011) model offers a suitably broad perspective for testing a range of leadership capabilities most likely relevant in an HE context.

\subsection{Content Validity of the Comparative Framework}

The 41 areas of capability devised in the study by Black, Groombridge and Jones (2011) are divided into four broad themes: Vision and Goals; Hands-on Leadership; Improvement and Learning; Work Details and the Big Picture. Can this framework of leadership capabilities be translated to the demands of the HE sector?

Strikingly, changing just a single word in 10 of the statements (e.g. "conservation" or "project" to "institution") plus minor rephrasing of only 4 other statements is required to redefine the framework for Higher Education. After translation (Table 2), the items remain relevant to the HE sector as a framework of Leadership Capabilities for Higher Education. The 4 statements requiring redefinition were revised as follows:

Statement 9: changed from "Advocate good governance, particularly in large complex projects" (Black, Groombridge, \& Jones, 2011) to "Advocate good governance: institutional, departmental, academic, and in complex projects” This change accounts for the major areas of governance within HE institutions (Middlehurst, 1999, 2004; Gayle, Tewarie, \& White, 2003).

Statement 19: changed from "Ensure that an understanding of what matters to biodiversity steers the work that people do" (Black, Groombridge, \& Jones, 2011) to "Ensure that an understanding of what matters to teaching \& research steers people's work”. This focus mirrors the generally-recognized purpose of HE institutions (Gibbons, 1998; del Sordo et al., 2012), but note that other aspects, such as enterprise and community outreach (Montesinos et al., 2008) might also be defined within a particular institution's vision and goals (Table 2, items 1 and 3).

Statement 29: changed from "Make improvements based on biodiversity needs and process performance, not arbitrary targets” (Black, Groombridge, \& Jones, 2011) to "Improvements are guided by understanding student, research \& process performance, not arbitrarily defined targets", drawing on the typical indicator areas for HE institutions (Alexander, 2000; Tam, 2001; del Sordo et al., 2012).

Statement 34: changed from "Establish budgets and a clear fund-raising strategy" (Black, Groombridge, \& Jones, 2011) to "Establish budgets and a clear fund-raising strategy (grants, fees, philanthropy, sponsorship)" highlighting the main income streams in HE (Liefner, 2003).

\subsection{Face Validity of the Proposed Leadership Framework}

The 41 capabilities defined in the proposed framework were compared to 15 leadership challenges identified in relation to the HE sector, as debated in literature and previously considered within this discussion (Table 3). The capabilities were considered and matched to the challenges to identify 1) whether any capabilities were unutilised in the mix of HE challenges and 2) whether any challenges could not be addressed by any of the leadership capabilities outlined in the framework. Each capability item was tested for relevance to each of the $15 \mathrm{HE}$ challenges, testing whether such a capability would assist in resolving or mitigating the challenge; essentially asking "would applying this area of competence (i.e. capability) enable the leader to either address the challenge or reduce its impact?”. As shown in Table 3 , the 41 areas of capability match with all 15 HE challenges.

\section{Discussion}

Identifying a suitable leadership framework in any sector is problematic; effective leadership behaviour must account for the leader, their followers and the context (Tannenbaum \& Schmidt, 1973). Also many frameworks proffer "to do" activities rather than "how to" methods (Bryman, 2007) which leaves leaders at risk of knowing what they should do but not knowing how, or when or where to do it, nor the potential impacts of such action.

A number of general frameworks of leadership have been presented in the HE literature. This discussion has evaluated whether general leadership considerations apply in the context the organisational challenges faced by leaders in Higher Education. The detailed framework of capabilities developed by Black, Groombridge and Jones (2011) appears to translate usefully to the demands of the HE sector. Both the translation of terms and the testing of subsequent items of capability against HE sector requirements suggest that the proposed framework of Leadership Capabilities for Higher Education is broadly valid (Table 2). 
Table 2. Leadership Capabilities for Higher Education adapted from Black, Groombridge \& Jones (2011) with single word changes to items marked ${ }^{*}$, other wording changes to items marked ${ }^{\dagger}$.

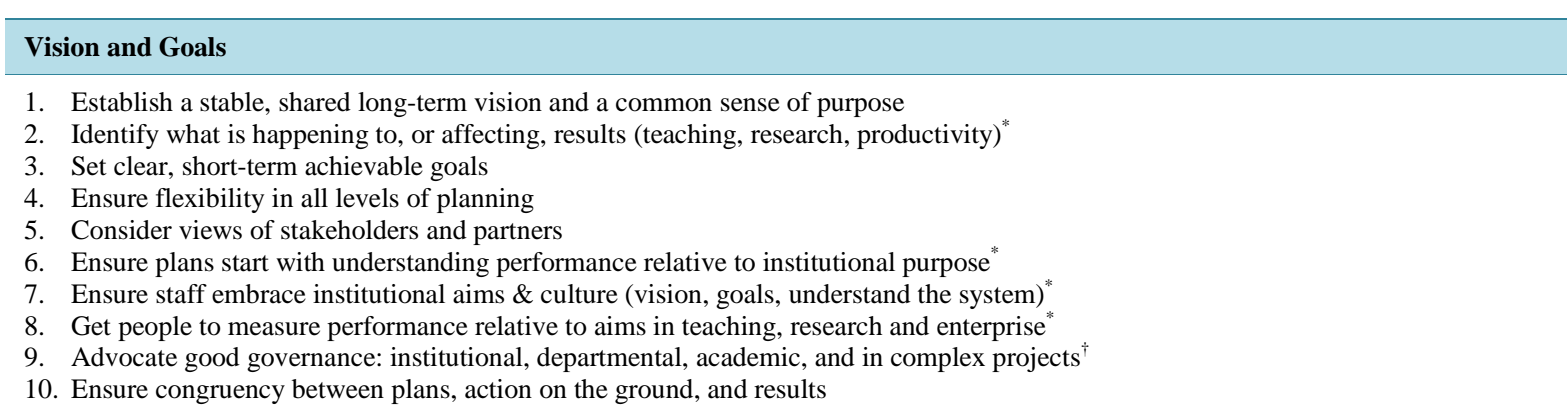

Hands-on Leadership

11. Be orientated towards 'hands-on' management, working with staff

12. Possess highly developed academic and/or operational skills appropriate to the institution ${ }^{*}$

13. Be able to prioritise the work by asking key questions

14. Know people's strengths; channel their energy and passion to maximum effect

15. Understand cultural differences and manage people's expectations and views sensitively

16. Check results with staff and empower them to get the job done

17. Involve the people doing the work in data analysis, decisions and implementing changes

18. Place responsibility and control of information in the hands of people who do the work

19. Ensure that an understanding of what matters to teaching \& research steers people's work ${ }^{\dagger}$

20. Have two-way communication meetings, with an emphasis on clarifying, testing \& listening

21. Ensure managers lead; spending time with staff, listening to concerns and enabling contributions

\section{Improvement and Learning}

22. Give people the opportunity to ask for training and provide it on a just-in-time basis

23. Be receptive to (and seek out) alternative solutions

24. Enable staff to challenge, share and learn from mistakes, without fear

25. Expect, and support staff, to strive for-high standards

26. Expect the institution (and its needs) to evolve through time*

27. Understand risk factors and make suitable contingencies

28. Judge the system rather than people; manage morale, celebrate success, learn from failures

29. Improvements are guided by understanding student, research \& process performance, not arbitrarily defined targets ${ }^{\dagger}$

30. Recognise the difference between neglect and lack of capability (training, experience, resources)

31. Allow people doing the work freedom to experiment with method to improve performance

\section{Work Details and the Big Picture}

32. Focus both internally and externally, understanding intra- and inter-organisational dynamics

33. Know the institution's sphere of influence and identify the solvable problems*

34. Establish budgets and a clear fund-raising strategy (grants, fees, philanthropy, sponsorship) ${ }^{\dagger}$

35. Examine financial and non-financial measures; which predict and cause institutional results ${ }^{*}$

36. Base information, technology and resource needs on how they help people's core work

37. Create attitude of co-operation with external partners, sharing information to improve work

38. Anticipate unexpected outcomes

39. Be prepared to seek specialist advice from external sources

40. Integrate management flexibility alongside professional and academic rigour*

41. Determine whether data on staff, communities or society would be useful to the institution*

Consideration of the 41 capabilities in Table 2 will highlight the risks associated with current leadership approaches within HE and should prompt a change in emphasis and approach. For example, the framework challenges perspectives on the role of middle managers, the inflexibility of institutional plans and procedures, the level to which people are engaged in their institutional vision, and how leaders inform themselves of how the organisation is performing.

To illustrate, it is possible to consider the first of these issues: the risk of underutilising middle managers (either in professional service roles or in academic leadership roles such as Directors of Studies or Directors of Research). The Leadership Capabilities framework prompts a senior leader, through items 8, 19, 21, 29 and 40 (Table 2), to reflect on whether middle managers are fully utilised not just in terms of analytical capability, but 
Table 3. Evaluation of Leadership Capability items with known challenges faced by HE leadership.

\begin{tabular}{|c|c|c|}
\hline & Challenge of Higher Education Leadership & $\begin{array}{c}\text { Items of Leadership Capability (Table 2) Which Address or } \\
\text { Reduce Impact of the Challenge }\end{array}$ \\
\hline 1) & Collaboration, partnership and interdisciplinarity & $5,11,17,19,20,23,24,32,37,39$ \\
\hline 2) & $\begin{array}{l}\text { Enhancing the student experience (teaching, extra-curricular, } \\
\text { employability) }\end{array}$ & $5,11,15,17,19,25,33$ \\
\hline 3) & Learning communities and learner-centred approaches & $5,11,12,14,15,17,19$ \\
\hline 4) & $\begin{array}{l}\text { Bureaucracy which stifles innovation and creates } \\
\text { inefficiency and ineffectiveness }\end{array}$ & $3,4,10,13,16,17,20,21,26,27,34,40$ \\
\hline 5) & Efficient use of resources & $2,4,6,10,16,17,18,21,22,33,34,35,36$ \\
\hline 6) & Combined role (teacher/research/citizen) & $8,9,11,12,14,17,19,20,22,29$ \\
\hline 7) & Collegial preference tending towards a self-serving culture & $7,15,17,20,21,24,30,31,37$ \\
\hline 8) & Transitional roles for academic leaders & $9,16,17,20,26,27$ \\
\hline 9) & $\begin{array}{l}\text { Conflicts between management and research aspects of } \\
\text { academic leader roles }\end{array}$ & $3,8,9,11,12,13,17,19$ \\
\hline 10) & $\begin{array}{l}\text { Differences between the demands encountered in } \\
\text { Professional, Academic and Senior leadership }\end{array}$ & $8,9,15,17,18,25,27,28,37$ \\
\hline 11) & Need to adapt and improve the organisation & $\begin{array}{c}1,2,3,6,10,15,17,18,20,22,23,25,26,27 \\
29,31,33,35,36,37,38,40,41\end{array}$ \\
\hline 12) & Individualism and external loyalties & $3,12,14,15,17,18,19,22,30$ \\
\hline 13) & Leading diversity and inclusion & $5,7,14,15,19,20,21,24,38,41$ \\
\hline 14) & Globalisation and internationalisation & $1,2,5,6,7,15,17,26,27,29,31,32,33,37,38,41$ \\
\hline 15) & Governance & $9,27,34,38,39,41$ \\
\hline
\end{tabular}

also their understanding of the needs, capabilities and motivations of staff, and their work knowledge (how things are operating on the ground) and how this information is provided to senior decision-makers. In a globalised, user-driven marketplace HE senior managers need to understand local capability (e.g. how schools, courses and research centres are performing) and local user needs (students, funders, professional bodies, business, donors) to inform how the institution needs to adapt its curriculum, services, research or operational activity (Figure 1). By seeking these perspectives, allied with a readiness to adapt goals and improve practices, senior leaders will essentially make changes in their management and leadership approach which will enable their institution to become more adaptive.

The capabilities described in Table 2 offer clearer guidance for the HE leader; but still provide room for interpreting "how". The framework demands the leader to think and evaluate the context of their work; essentially the items as represented require the leader to perceive and evaluate their work in a new way. Leadership development is self-development (Kouzes \& Posner, 2007) and leaders need to learn to think critically about their roles (Amey, 2006). An effective framework of leadership capabilities should provide the type of scope and guidance shown in Table 2 to enable this kind of critical reflection.

For example taking item 5 "Consider the views of external stakeholders and partners" (Table 2), as a working principle this has practical value for reflecting on practice: "when I build vision do I consider views of external stakeholders and partners?”; "when I set goals do I consider the views of external stakeholders and partners?”; "when I give recognition to a team do I consider external stakeholders and partners?" and so on. Clearly in these instances the leader has discretion; is such behaviour relevant or important? Should it be done or not done? This demands that, at the very least, the leader is able to become conscious of their decision, rather than fall into unhelpful assumptions, unconscious bias or unwitting ineffectiveness. The same approach can be applied when reflecting upon, understanding and considering the other 40 items in relation to personal leadership practice.

Effective leaders will consciously develop new approaches and remain awake to their own practice and its relevance to work (Figure 2). Leaders need to develop personal mastery in the way that they comprehend and operate, progressing beyond competence and values, towards a proficiency based on a clear understanding of 


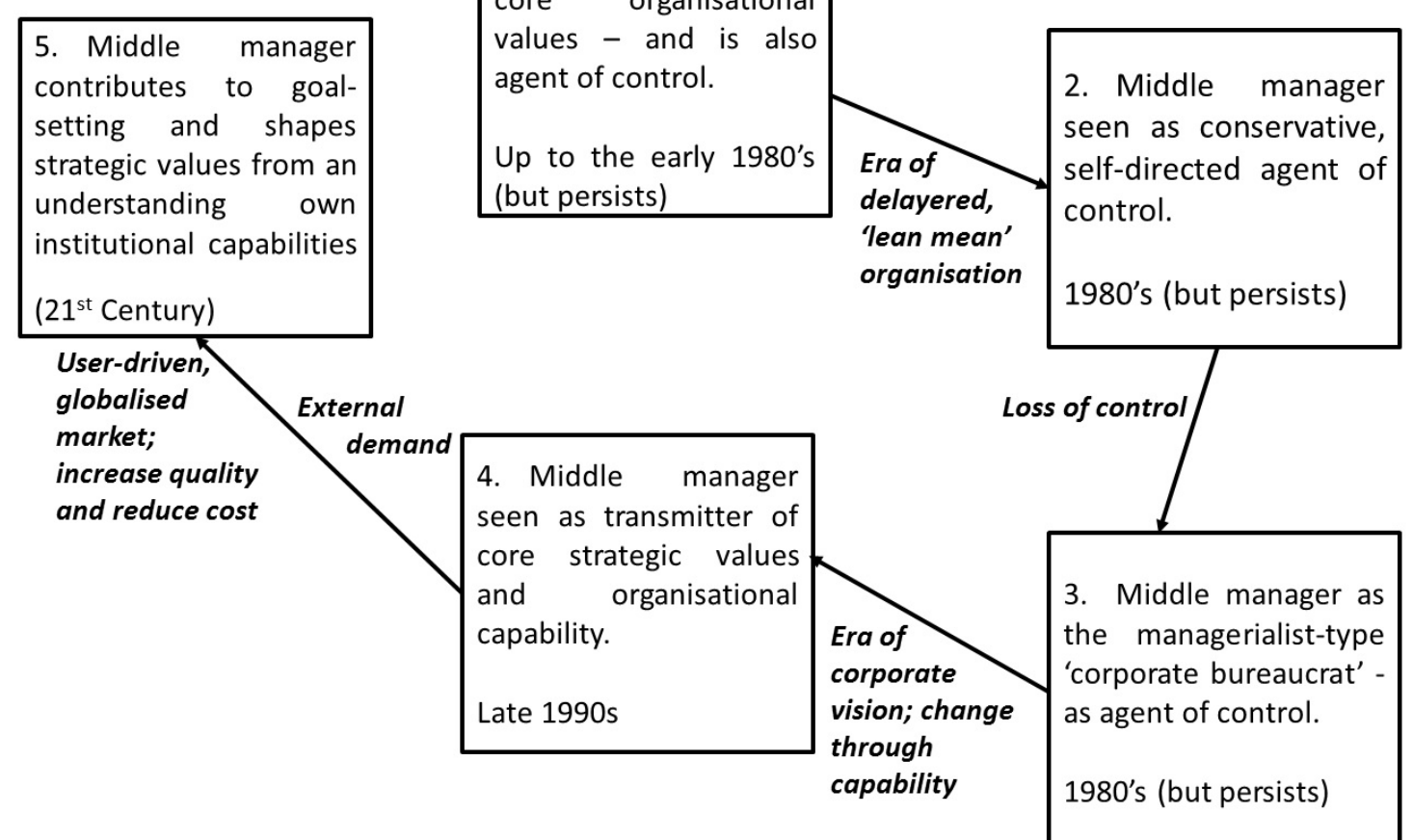

Figure 1. Conceptualising the evolution of leadership challenges for middle managers in Higher Education for the $21^{\text {st }}$ century (figure adapted from Clegg \& McAuley, 2005).

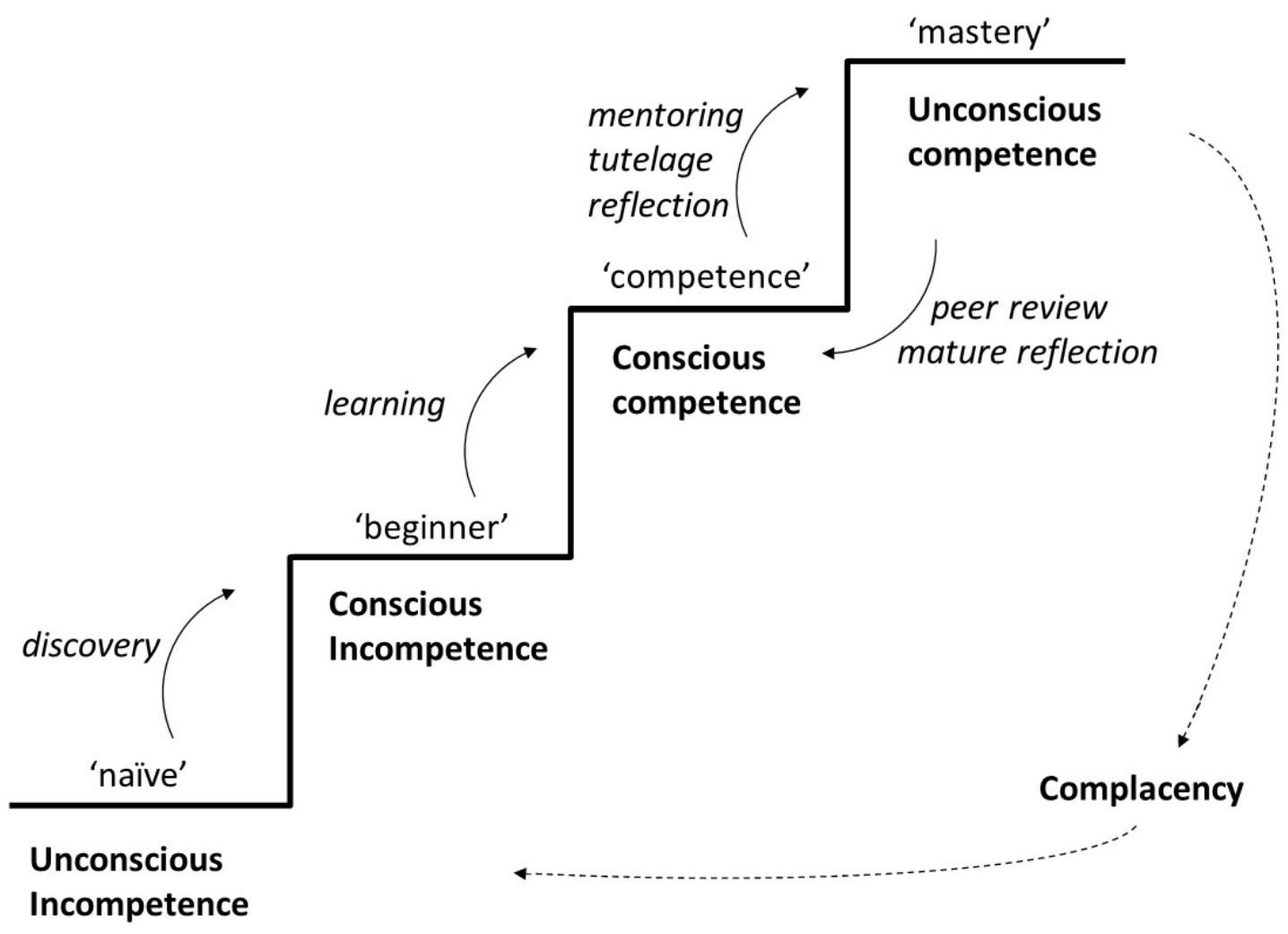

Figure 2. The ladder of competence development (adapted from concepts summarised by Robinson, 1974). 
context and purpose (Senge, 1990). An effective leader recognises that there is always room for improvement, which requires a sense of humility and respect for the needs of others (Kouzes \& Posner 2007).

\section{Conclusion}

Current frameworks of leadership for the Higher Education sector do not encompass all of the behaviours expressed in established leadership literature. Higher Education leaders need a combination of leadership and management competencies in order to address the challenges faced in the sector; separation of these facets is counterproductive and will not address the negative impact of managerialism perceived within institutions. The framework developed in this analysis offers a suitable range of approaches for leaders in HE. Within a changing world an effective leader must be both student and teacher (Kotter, 1996): always hungry to learn more about how to enthuse, engage and empower those who follow. For staff in academic positions, becoming a "learner" may be uncomfortable, so these individuals should be encouraged, through the active, visible and credible example of seniors and peers, to appreciate the benefits and necessity of personal leadership development.

\section{References}

Adair, J. (1979). Action-Centred Leadership. Aldershot, United Kingdom: Gower.

Alexander, F. K. (2000). The Changing Face of Accountability: Monitoring and Assessing Institutional Performance in Higher Education. The Journal of Higher Education, 71, 411-431. http://dx.doi.org/10.2307/2649146

Altbach (2011). The Past, Present, and Future of the Research University. In P. G. Altbach, \& J. Salmi, (Eds.), The Road to Academic Excellence (pp. 11-32). Washington DC: The World Bank.

Amey, M. J. (2006). Leadership in Higher Education, Change: The Magazine of Higher Learning, 38, 55-58.

Astin, A. W., \& Astin, H. S. (2000). Leadership Reconsidered: Engaging Higher Education in Social Change. Battle Creek, MI: W.K. Kellogg Foundation.

Bass, B. M. (1997). Does the Transactional-Transformational Leadership Paradigm Transcend Organizational and National boundaries? American Psychologist, 52, 130-139. http://dx.doi.org/10.1037/0003-066X.52.2.130

Bass, B. M., \& Avolio, B. J. (1993). Transformational Leadership and Organizational Culture. Public Administration Quarterly, 17, 112-121.

Bennis, W. (1999). The Leadership Advantage. Leader to Leader, 12, 18-23. http://dx.doi.org/10.1002/ltl.40619991205

Bennis, W. (2009). On Becoming a Leader (Revised Edition). New York: Addison-Wesley Publishing.

Black, S. A., \& Copsey, J. A. (2014a). Does Deming’s “System of Profound Knowledge” Apply to Leaders of Biodiversity Conservation? Open Journal of Leadership, 3, 53-65. http://dx.doi.org/10.4236/ojl.2014.32006

Black, S. A., \& Copsey, J. A. (2014b). Purpose, Process, Knowledge and Dignity in Interdisciplinary Projects. Conservation Biology, 28, 1139-1141. http://dx.doi.org/10.1111/cobi.12344

Black, S. A., Groombridge, J. J., \& Jones, C. G. (2011). Leadership and Conservation Effectiveness: Finding a Better Way to Lead. Conservation Letters, 4, 329-339. http://dx.doi.org/10.1111/j.1755-263X.2011.00184.X

Black, S. A., Groombridge, J. J., \& Jones, C. G. (2013). Using Better Management Thinking to Improve Conservation Effectiveness. ISRN Biodiversity, 2013, Article ID: 784701.

Black, S. A., Meredith, H. M. R., \& Groombridge, J. J. (2011). Biodiversity Conservation: Applying New Criteria to Assess Excellence. Total Quality Management, 22, 1165-1178. http://dx.doi.org/10.1080/14783363.2011.624766

Bryman, A. (2007). Effective Leadership in Higher Education: A Literature Review. Studies in Higher Education, 32, 693710. http://www.tandfonline.com/ http://dx.doi.org/10.1080/03075070701685114

Clegg, S., \& McAuley, J. (2005). Conceptualising Middle Management in Higher Education: A Multifaceted Discourse. Journal of Higher Education Policy and Management, 27, 9-34, http://dx.doi.org/10.1080/13600800500045786

D’Amico, R., Vermigli, P., \& Canetto, S. S. (2011). Publication Productivity and Career Advancement by Female and Male Psychology Faculty: The Case of Italy. Journal of Diversity in Higher Education, 4, 175-184. http://dx.doi.org/10.1037/a0022570

Davies, J., Hides, M. T., \& Casey, S. (2001). Leadership in Higher Education. Total Quality Management, 12, 1025-1030, http://dx.doi.org/10.1080/09544120120096197

Deem, R. (1998). “New Managerialism” and Higher Education: The Management of Performances and Cultures in Universities in the United Kingdom. International Studies in Sociology of Education, 8, 47-70.

http://dx.doi.org/10.1080/0962021980020014 
Defazio, D., Lockett, A., \& Wright, D. M. (2009). Funding Incentives, Collaborative Dynamics and Scientific Productivity: Evidence from the EU Framework Program. Research Policy, 38, 293-305. http://dx.doi.org/10.1016/j.respol.2008.11.008

del Sordo, C., Orelli, R. L., Padovani, E., \& Gardini, S. (2012). Assessing Global Performance in Universities: An Application of Balanced Scorecard. Procedia-Social and Behavioral Sciences, 46, 4793-4797. http://dx.doi.org/10.1016/j.sbspro.2012.06.336

Deming, W. E. (1982). Out of the Crisis. Cambridge, MA: MIT Center for Advanced Engineering Study.

ECU (Equality Challenge Unit) (2015). Athena SWAN Charter. http://www.ecu.ac.uk/equality-charter-marks/athena-swan/

Etzkowitz, H., Kemelgor, C., Neuschatz, M., Uzzi, B., \& Alonzo, J. (1994). The Paradox of Critical Mass for Women in Science. Science, 266, 51-54. http://dx.doi.org/10.1126/science.7939644

Garforth, L., \& Kerr, A. (2009). Women and Science: What's the Problem? Social Politics, 16, 379-403. http://dx.doi.org/10.1093/sp/jxp015

Gayle, D. J., Tewarie, B., \& White, A. Q. (2003). Governance in the Twenty-First-Century University: Approaches to Effective Leadership and Strategic Management: ASHE-ERIC Higher Education Report. San Francisco, CA: Jossey-Bass.

Gibbons, M. (1998). Higher Education Relevance in the 21st Century. Washington DC: World Bank.

Goffee, R., \& Jones, G. (2009). Clever: Leading Your Smartest, Most Creative People. Boston, MA: Harvard Business Press. Goleman, D. (1997). Emotional Intelligence. New York: Bantam.

Hamel, G. (2009). Moonshots for Management. Harvard Business Review, 87, 91-98.

Heifetz, R. A., \& Laurie, D. L. (1997). The Work of Leadership. Harvard Business Review, 75, 124-134.

Hersey, P., \& Blanchard, K. H. (1969). Life Cycle Theory of Leadership. Training Development, 23, 26-34.

Herzberg, F. (1976). One More Time: How Do You Motivate Employees? Harvard Business Review, 81, 87-96.

Huy, Q. M. (2001). In Praise of Middle Managers. Harvard Business Review, 79, 72-79.

Kanter, R. M. (2003). Leadership and the Psychology of Turnarounds. Harvard Business Review, 81, 58-67.

Kennedy, C. (1994). Managing with the Gurus. London: Random House.

Kotter, J. P. (1996). Leading Change. Boston, MA: Harvard Business School Press.

Kouzes, J. M., \& Posner, B. Z. (2007). The Leadership Challenge (4th ed.). San Francisco, CA: Jossey-Bass Publishers.

Krantz, J., \& Gilmore, T. N. (1990). The Splitting of Leadership and Management as a Social Defense. Human Relations, 43, 183-204. http://dx.doi.org/10.1177/001872679004300206

Liefner, I. (2003). Funding, Resource Allocation, and Performance in Higher Education Systems. Higher Education, 46, 469-489. http://dx.doi.org/10.1023/A:1027381906977

Macdonald, J. (1998). Calling a Halt to Mindless Change. New York: American Management Association International.

McGregor, D. M. (1957). The Human Side of Enterprise. Management Review, 46, 22-28.

Middlehurst, R. (1999). New Realities for Leadership and Governance in Higher Education? Tertiary Education and Management, 5, 307-329. http://dx.doi.org/10.1080/13583883.1999.9966999

Middlehurst, R. (2004). Changing Internal Governance: A Discussion of Leadership Roles and Management Structures in UK Universities. Higher Education Quarterly, 58, 258-279. http://dx.doi.org/10.1111/j.1468-2273.2004.00273.x

Mintzberg, H. (2009a). Managing. San Francisco, CA: Berrett-Koehler.

Mintzberg, H. (2009b). Rebuilding Companies as Communities. Harvard Business Review, 87, 140-143.

Montesinos, P., Carot, J. M., Martinez, J.-M., \& Mora, F. (2008). Third Mission Ranking for World Class Universities: Beyond Teaching and Research. Higher Education in Europe, 33.

Oakland, J. S. (2001). Total Organizational Excellence; Achieving World Class Performance. Oxford: Butterworth-Heinemann.

Peters, T., \& Waterman, R. H. (1982). In Search of Excellence. New York: Harper Row.

Robinson, W. L. (1974). Conscious Competency—The Mark of a Competent Instructor. The Personnel Journal—Baltimore, 53, 538-539

Rummler, G., \& Bache, A. (1995). Improving Performance: How to Manage the White Space in the Organization Chart. San Francisco, CA: Jossey-Bass.

Schofer, E., \& Meyer, J. W. (2005). The Worldwide Expansion of Higher Education in the Twentieth Century. American Sociological Review, 70, 898-920. http://dx.doi.org/10.1177/000312240507000602

Scholtes, P. R. (1998). The Leader's Handbook: Making Things Happen, Getting Things Done. New York: McGraw Hill. 
Seddon, J. (2003). Freedom from Command and Control. Buckingham: Vanguard Press.

Senge, P. (1990). The Fifth Discipline. New York: Doubleday.

Shewhart, W. (1931). Economic Control of Quality of Manufactured Product. New York: Van Nostrand Company.

Slater, R. (1999). Jack Welch and the GE Way: Management Insights and Leadership Secrets of the Legendary CEO. New York: McGraw-Hill.

Tam, M. (2001). Measuring Quality and Performance in Higher Education. Quality in Higher Education, 7, 47-54. http://dx.doi.org/10.1080/13538320120045076

Tannenbaum, R., \& Schmidt, W. H. (1973). How to Choose a Leadership Pattern. Harvard Business Review, 51, $162-180$.

Tourish, D. (2008). Challenging the Transformational Agenda: Leadership Theory in Transition? Management Communication Quarterly, 21, 522-528. http://dx.doi.org/10.1177/0893318907313713

Womack, J. P., \& Jones, D. T. (1996). Lean Thinking: Banish Waste and Create Wealth in Your Corporation. London: Simon \& Schuster. 